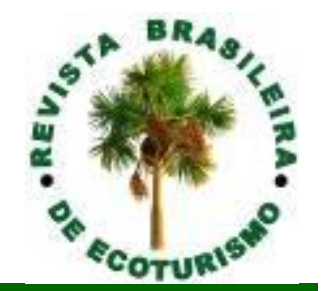

\title{
Cidades-patrimônio e espaços de lazer: equipamentos de lazer no Centro Histórico de São Luís (MA)
}

\author{
Patrimony cities and leisure spaces: leisure equipments in \\ São Luís's (MA, Brazil) Center Historic
}

\author{
Andréia Maciel Santos Moutinho, Klautenys Dellene Guedes Cutrim
}

\section{RESUMO:}

O presente artigo pretende investigar o Centro Histórico de São Luís (MA), analisando e catalogando os principais equipamentos específicos de lazer e atividades oferecidas sistematicamente no bairro da Praia Grande, na perspectiva de uma contribuição para conhecimento e desenvolvimento da área, bem como discutir o papel do lazer no desenvolvimento e preservação de espaços de patrimônio histórico-cultural buscando fortalecer o segmento do turismo cultural na cidade. Para que o objetivo geral fosse alcançado, foi necessário identificar esses equipamentos verificando através de visitas o seu uso e funcionamento para possíveis apontamentos de alternativas e utilização para os visitantes. Esse trabalho é um estudo descritivo de caráter qualitativo derivado de pesquisas bibliográficas para a construção da fundamentação teórica e pesquisa de campo a partir da observação do espaço. Os principais resultados da pesquisa apontam para um grande acervo de equipamentos de lazer no centro histórico, mas que infelizmente pouco ou nada estão sendo utilizados para esse fim, apontamos algumas problemáticas observadas nesses equipamentos como inflexibilidade nos horários e dias de abertura para o público, a pouca divulgação e dinamização desse espaço bem com a falta de uma programação catalogada e divulgada para atrair os visitantes turistas e locais.

PALAVRAS-CHAVE: Espaços de Lazer; Patrimônio; Centro Histórico de São Luís (MA).

\section{ABSTRACT}

This article intends to investigate the Center Historic of São Luis (MA), analyzing and cataloging the main specific leisure equipments and activities offered systematically in the Praia Grande neighborhood, on the perspective of a contribution for the knowledge and development of the area, as well as discuss the job of leisure on the development and preservation in the historical and cultural patrimony spaces, looking for strengthening the cultural tourism segment in the city. So the general goal can be achieved, it was necessary to identify these equipments, verifying through visits its use and operation for possible notes on alternatives and use for the visitors. This work is a descriptive study of qualitative character coming from bibliographic researches for the construction of the theoretical grounding and field researches rom the observation of the space. The main results of the research point to a great collection of leisure equipments in this historic centre, but that, unfortunately, a little or nothing at all are being utilized for this function, we pointed out some problematic situations observed in these equipment such as inflexibility on the schedules and public opening days, the lack of disclosure and promotion of this space, as well as a missing catalogued and spreaded programming to attract the local and tourist visitors.

KEYWORDS: Leisure Spaces; Patrimony; São Luís's Center Historic. 


\section{Introdução}

A pesquisa ora apresentada e que se coloca, focando a relação entre as categorias espaços de lazer, patrimônio e centro histórico, investiga o Centro Histórico de São Luís (MA), analisando e catalogando os principais equipamentos específicos de lazer e atividades oferecidas sistematicamente no bairro da Praia Grande, na perspectiva de uma contribuição para conhecimento e desenvolvimento da área, bem como discutir o papel do lazer no desenvolvimento e preservação de espaços de patrimônio histórico-cultural buscando fortalecer o segmento do turismo cultural na cidade.

O lazer como uma problemática tipicamente urbana, característica, sobretudo, das grandes cidades, onde democratizá-lo implica em, igualmente, democratizar o espaço (MARCELLINO; BARBOSA; MARIANO, 2006). Tal compreensão articula-se em torno do espaço do Centro Histórico de São Luís (MA), cidade titulada como Patrimônio Cultural Mundial ${ }^{1}$, uma área viva e vibrante integrada à vida cotidiana da cidade e que funciona como um lugar para o desenvolvimento de atividades culturais tradicionais, portanto, observada como relevante para um estudo que amplie as contribuições teóricas e metodológicas acerca deste objeto. Trata-se de um olhar direcionado aos "centros históricos", enquanto dimensão da metalinguagem do patrimônio que prestam-se a ações pedagógicas, turísticas, políticas, econômicas e de experiências técnicas e sociais (GUILLAUME; ASHWORTH; TUNBRIDGE apud PEIXOTO, 2003).

Desta forma, a crescente demanda e apropriação das cidades históricas como espaço de lazer por diferentes segmentos aponta para a necessidade de um estudo mais aprofundado deste aspecto e suas conexões com a questão cultural e patrimonial. Como destaca Peixoto (2003, p. 222), os "centros históricos" são apresentados como a expressão concreta de uma ideia de espaço público que permite que a cidade seja imaginada e transformada a partir do seu passado e onde uma ideia de patrimônio se conecta com uma ideia de espaço público para ser potencializada como atração turística e de lazer.

Assim sendo, o objetivo geral deste trabalho, propõe-se estudar o Centro Histórico de São Luís (MA), tendo-se como referência equipamentos específicos de lazer na perspectiva de uma contribuição para conhecimento e desenvolvimento da área. Para isso, foi necessário identificar esses equipamentos verificando através de visitas o seu uso e funcionamento, catalogando os principais equipamentos e/ou atividades oferecidas de lazer no Centro Histórico, para possíveis apontamentos de alternativas e utilização para os visitantes, bem como discutir o papel do lazer para o desenvolvimento de espaços de patrimônio histórico-cultural e contribuir com orientações teórico-metodológicas voltadas para o (re)ordenamento e (re)aproveitamento das potencialidades do centro histórico para as práticas que colaborem com uma ressignificação desse espaço e seu desenvolvimento sociocultural e econômico.

Tratamos das informações encontradas através de uma postura qualitativa, cuja proposta metodológica para a realização da pesquisa dá-se através da combinação de pesquisa bibliográfica e observação. A pesquisa qualitativa responde a questões muito particulares, preocupando-se com a 
realidade que não pode ser quantificada e corresponde a um espaço mais profundo das relações, trabalhando com os significados. Nos termos de Cruz Neto (1994, p. 51), "na pesquisa qualitativa, o trabalho de campo se apresenta como uma possibilidade de conseguirmos não só uma aproximação com aquilo que desejamos conhecer e estudar, mas também de criar um conhecimento, partindo da realidade presente no campo".

Quanto aos fins será uma pesquisa exploratório e descritiva do objeto de estudo. Richardson (1999, p. 66) diz que os estudos descritivos vinculamse ao propósito de se descrever as características de um fenômeno e os estudos exploratórios quando não se tem informação sobre determinado tema e se deseja conhecer o fenômeno. Esse trabalho é um estudo descritivo de caráter qualitativo derivado de pesquisas bibliográficas para a construção da fundamentação teórica e pesquisa de campo a partir da observação do espaço. Em relação à pesquisa descritiva foi realizada a partir dos fatos observados e registrados, não havendo interferência do pesquisador. Para a coleta de dados, utilizou-se como procedimento metodológico a pesquisa de campo para aprofundamento de conhecimentos relacionados ao objeto de estudo sendo realizada durante os meses de março e abril de 2015 no Centro Histórico de São Luís (MA).

O Centro Histórico de São Luís (MA) é formado por 11(onze) bairros. Dentre estes, o denominado bairro da Praia Grande que corresponde ao ambiente investigado. Esse universo foi escolhido por conter a maior concentração de patrimônio histórico permitindo-nos aprofundamento e abrangência da compreensão e análise mais aprofundada das representações e motivações. Os Espaços configuram-se, portanto, como alvos para as discussões, observações e a tessitura da análise das dinâmicas que envolvem sua interface, pretensão articulada a partir de um retorno ao referencial teórico adotado e aos resultados empíricos que, juntos, deverão favorecer o exercício da composição teórico-metodológica que se pretende ser a contribuição da análise do espaço de lazer do Centro Histórico de São Luís (MA).

O lazer aqui é entendido como: "[...] uma dimensão da cultura constituída por meio da vivência lúdica de manifestações culturais em um tempo/espaço conquistado pelo sujeito ou grupo social, estabelecendo relações dialéticas com as necessidades, os deveres e as obrigações" (GOMES, 2004, p.124). Este lazer é, assim, um instrumento por meio do qual é possível se pensar questões relevantes como a "conversão" dos núcleos históricos das cidades em "museus ao ar livre" com foco em seus diferentes conteúdos como o turismo, mas também ante as relações de trabalho e de habitação que se processam nesses mesmos espaços, o perfil dos públicos frequentadores e residentes, as ameaças de descaracterização em função de ações abusivas e unicamente focadas em determinados tipos de atividades (como as lúdicas), podendo mesmo comprometer a fixação de residentes e agravar o despovoamento já existente, dentre outras (SEBASTIÃO, 2010).

Desta maneira, tais aspectos apontaram a necessidade de estudos e análises das singularidades do tema em questão, proposto a partir do fenômeno do lazer enquanto categoria viável para se pensar seu desenvolvimento e importância social. Tais premissas são colocadas como 
relevantes para a constituição do problema de pesquisa, assente na interrogativa sobre quais equipamentos de lazer encontramos no bairro da Praia Grande no Centro Histórico de São Luís (MA).

Abordar tais aspectos sob a perspectiva do lazer configura-se como de relevância científica e social, pois trata-se de um fenômeno que extrapola os limites de estudo de uma área específica, permitindo relações e diálogos com vários campos do saber, favorecendo a interdisciplinaridade, justificando-se, portanto, como um estudo que o problematiza a partir da dinâmica sociocultural, econômica e patrimonial em um contexto urbano. Acredita-se que é possível trazer uma contribuição para o debate quanto à promoção e o (re)aproveitamento das potencialidades do Centro Histórico de São Luís (MA) com base neste recorte especifico; e, também contribuir, com o tema das políticas públicas em torno da análise e projeção de orientações acerca das práticas lúdicas no espaço em torno de uma ressignificação deste espaço e seu desenvolvimento.

Ao encontro de tal abordagem é oportuna a participação de Marcellino (1995, p. 18) quando destaca que a "especificidade concreta" do lazer deverá levar em conta o seu entendimento amplo em termos de conteúdo, as atitudes que envolve, os valores que propicia, a consideração dos seus aspectos educativos, as suas possibilidades como instrumento de mobilização e de participação cultural, e as barreiras socioculturais verificadas para seu efetivo exercício, tanto intraclasses como interclasses sociais.

Conforme situado, compreendemos o tema exposto na perspectiva da discussão sobre as apropriações e difusão dos patrimônios materiais. Com a crescente demanda e apropriação das cidades históricas como espaço de lazer, e sua representação para os visitantes, vimos à necessidade de uma investigação mais aprofundada entre o lazer e a implicações culturais e patrimoniais, pois entendemos que a ocorrência do lazer nos centros históricos sem perspectivas de preservação do patrimônio deixaria de contribuir na realização de uma continuidade cultural, na recriação desses espaços e no desenvolvimento histórico-cultural. Tal compreensão conduz ao propósito de refletir acerca do espaço de lazer que colocamos como centro Histórico e seus equipamentos de lazer.

Assim, as reflexões mencionadas só podem ser feitas a partir da resposta a uma questão mais abrangente, qual seja: como vem se configurando a apropriação do Centro Histórico de São Luís (MA) como espaço de lazer?

A partir do problema apresentado, decorre a seguinte pergunta de pesquisa: quais equipamentos de lazer encontramos no bairro da Praia Grande no Centro Histórico de São Luís do MA?

Para isso, a proposta de estudo pressupõe a adoção de encaminhamentos teórico-metodológicos que subsidie a discussão em torno da questão sugerida, a fim de contribuir para uma análise do (re)conhecimento dos equipamentos de lazer no Centro Histórico 


\section{O lazer e cidades-patrimônio}

Ao tratar a temática do lazer faz-se necessário destacar que sua abordagem dá relevo a uma visão centrado no ser humano e na sociedade. É comum relacionarmos o termo "lazer" ao conteúdo da atividade e a questão do prazer, como aponta Marcellino (2006). Contudo, o conteúdo da ação não constitui condição suficiente para a definição de lazer, mas as circunstâncias que cercam o desenvolvimento dos vários conteúdos são básicas para a sua caracterização, nesse sentido, o autor considera como fundamentais os aspectos tempo e atitude.

Ao apontar a atitude e o tempo como aspectos fundamentais para caracterizar o lazer, Marcellino (2006) fundamenta-se principalmente nos estudos do sociólogo francês Joffre Dumazedier e sua visão de que lazer é, inicialmente, liberação e prazer, sobre o qual incide três categorias que correspondem às suas funções mais importantes: a) função de descanso; b) função de divertimento, recreação e entretenimento; c) função de desenvolvimento. Para Dumazedier (2000, p.34), "as três funções são solidárias, estão sempre intimamente unidas umas às outras, mesmo quando parecem opor-se entre si. [...] podem suceder-se ou coexistir; manifestar-se uma de cada vez ou simultaneamente na mesma situação de lazer".

Gomes (2004) faz uma leitura sobre o lazer relacionado a cultura e nos afirma a necessidade de superar o entendimento restrito de lazer como cultura, pois, associar o lazer com a cultura ressalta a importância de aprofundarmos conhecimentos sobre esta última. Pois o lazer é uma das importantes dimensões da cultura, assim como o trabalho, a educação, a família, dentre outras.

Entendo o lazer como uma dimensão da cultura constituída por meio da vivencia lúdica de manifestações culturais em um tempo/espaço conquistado pelo sujeito ou grupo social, estabelecendo relações dialéticas com as necessidades, os deveres e as obrigações, especialmente com o trabalho produtivo.

Antunes (2001) compreende que na vida há a necessidade de uma atividade vital, cheia de sentido e autodeterminada, sem barreiras entre 0 tempo de trabalho e o tempo de não trabalho, que possibilite desenvolver uma nova sociabilidade. O lazer pensado sob estas condições supera a possibilidade de sua utilização como fonte de alienação e de consumo, supera sua visão funcionalista e sua condição de mercado.

$\mathrm{Na}$ perspectiva de usos e acesos, a democratização do lazer implica, assim, na democratização dos espaços de lazer e, na lógica social moderna o espaço do lazer é o espaço urbano, ou seja, o processo de urbanização e industrialização é que concretizou a forma de lazer vivenciado na atualidade, e, nesse sentido, delimitou locais onde, no tempo adequado, o lazer deve ser vivenciado. Nesse sentido, os arranjos sociais do modo de produção atual, lançam cada vez mais equipamentos, muitos deles não específicos, mas que atendem também o interesse do lazer como os shoppings, ou criam outros espaços não urbanos destinados ao público urbano, como o lazer na natureza. 
Nessa lógica de atrelamento ao espaço urbano o lazer precisa ter seu lugar. Marcellino (2006), chama esse espaço de equipamento e classifica-os como equipamentos específicos e equipamentos "não-específicos" de lazer. Os equipamentos não específicos de lazer são espaços não construídos de modo particular para o lazer, mas que podem, eventualmente, ser utilizado para tanto. O lar é o principal deles, onde a maioria da população urbana desenvolve suas atividades de lazer no tempo livre. Outros equipamentos que se encaixam nessa categoria são os bares, as ruas, as escolas entre outros.

Com relação a democratização desses espaços de lazer, Martignoni (2013) acrescenta que é fundamental o aprofundamento da questão, pois o avanço da racionalidade econômica moderna, que aprofunda a forma de mercadoria do lazer e privatiza os espaços, permite acesso somente aqueles que tem melhores condições socioeconômicas. De outra forma, iniciativas econômicas mais lucrativas substituem espaços destinados ao lazer, como em teatros e cinemas. As políticas públicas relacionadas ao lazer, muitas vezes, por interesses privados, são desconsideradas e destinam áreas que deveriam ser implementadas com equipamentos para o lazer para outros empreendimentos, assim o espaço para o lazer se torna privilégio pela síntese histórica das transformações da área central de São Luís, se depreende que o Poder Público sempre se voltou, da maneira mais pragmática possível, para o atendimento das necessidades das camadas de alta renda, provocando com isso sucessivos processos de abandono e degradação de bairros. (BURNETT, 2007)

Nesse sentido, além da busca por políticas públicas que garantam a obtenção de novos espaços de lazer democráticos e que todos tenham acesso, é preciso lutar pela manutenção dos espaços existentes e sua adequada utilização. Outra questão relevante com relação ao espaço destinado ao lazer reside no fato de não serem consideradas as características culturais e sociais locais, os espaços são construídos a partir de uma ideia universal de lazer e dessa forma o próprio espaço orienta a universalização de atitudes, desconsiderando o tecido social que dá vida a determinada localidade. Martignoni (2013, p. 34) nos coloca que:

As formas lúdicas tradicionais se organizavam a partir do local, das relações sociais localizadas, a cultura era transmitida, construída e reconstruída pela presença, pelo contato entre os sujeitos. O espaço era a própria comunidade onde a vida, em todas as suas dimensões, se realizava, a produção e a reprodução da vida social e cultural se dava na relação direta com o ambiente. O dinamismo da modernidade através da reordenação tempo e espaço permite o deslocamento das relações sociais de contextos locais de interação. Gradativamente começam a surgir o espaço para o trabalho, o espaço para morar e o espaço para o lazer, e isso necessariamente não precisa ter nenhuma ligação cultural, o lugar não é mais a expressão de todas as dimensões da vida.

Importante é, assim, a contribuição dos estudos de Burnett, referencial para intervenções, usos e apropriações dos sítios históricos e Venâncio (2002; 2007) que faz um passeio sobre "habitar contemporâneo no patrimônio 
cultural urbano", "a vida cotidiana no centro histórico de São Luís”. Já Carvalho $(2009$; 2012) ao problematizar o Turismo e a preservação do patrimônio cultural na visão de moradores do bairro Praia Grande em São Luís e analisando o modelo de preservação do Centro Histórico da cidade em termos de seu uso social e turístico ajuda a construir uma caracterização do espaço, compreendendo o contexto de sua formação e desenvolvimento juntamente com seus residentes.

Relevante também é pensar a permanência da vida local no Patrimônio da Humanidade que revela a redescoberta do lugar, revela uma intenção e uma prática que se coloca em direta oposição da construção dos lugares homogêneos e petrificados desenhados para o mercado porque valoriza 0 uso, o contexto, o habitat, os moradores como diz Arantes (2000).

As leituras dos autores citados, dentre outros que oportunamente buscamos, auxiliaram na compreensão e análise dos objetos delineados nesta pesquisa, aspecto que se coloca em sintonia com o fato de haver uma aproximação da autora com o Centro Histórico, o que tornou possível, ainda, a construção de uma imagem de seu espaço físico e cultural e o (re)conhecimento das dinâmicas sociais que o tornam "vivo".

\section{O centro histórico de São Luís (MA)}

O Centro Histórico do Município de São Luís situa-se na faixa costeira noroeste do município, na confluência dos rios Anil e Bacanga (Figura 1). A área de abrangência desse Centro compreende o núcleo primitivo da cidade, no platô fronteiriço à foz dos rios mencionados. O Centro Histórico de São Luís compreende uma área de 220 hectares de extensão em São Luís, capital do Maranhão. Cerca de 2500 imóveis estão tombados pelo patrimônio histórico estadual, e 1000 pelo Instituto do Patrimônio Histórico e Artístico Nacional (GONÇALVES, 2006).

O Bairro Praia Grande possui uma longa história. É o espaço originário da cidade de São Luis e desde 1979 vem sendo contemplado pelo programa de revitalização, com períodos de maior ou menor dinâmica, continuando em andamento até os dias de hoje. Exatamente por isso, a partir dele é possível observar concretamente as mudanças de abordagens em relação ao trato da área central e como vem se modificando (SILVA; SILVA, 2010,p.5).

Foi declarado Patrimônio Mundial em 1997, por seu conjunto arquitetônico colonial português adaptado ao clima do local. O Bairro da praia Grande é uma dos 11 (onze bairros) que compõe o Centro Histórico de São Luís. Ele é um bairro comercial cuja consolidação se deu a partir de 1789, em decorrência da ampliação das atividades portuárias da cidade, no embalo da grande produção de algodão para exportação, grandes firmas comerciais estabeleceram-se no bairro para usufruir dos benefícios portuários tornando a Praia Grande o centro econômico mais importante da cidade até sua progressiva deteriorização, ocasionada pela desaparecimento das firmas comerciais e abandono dos sobrados. 


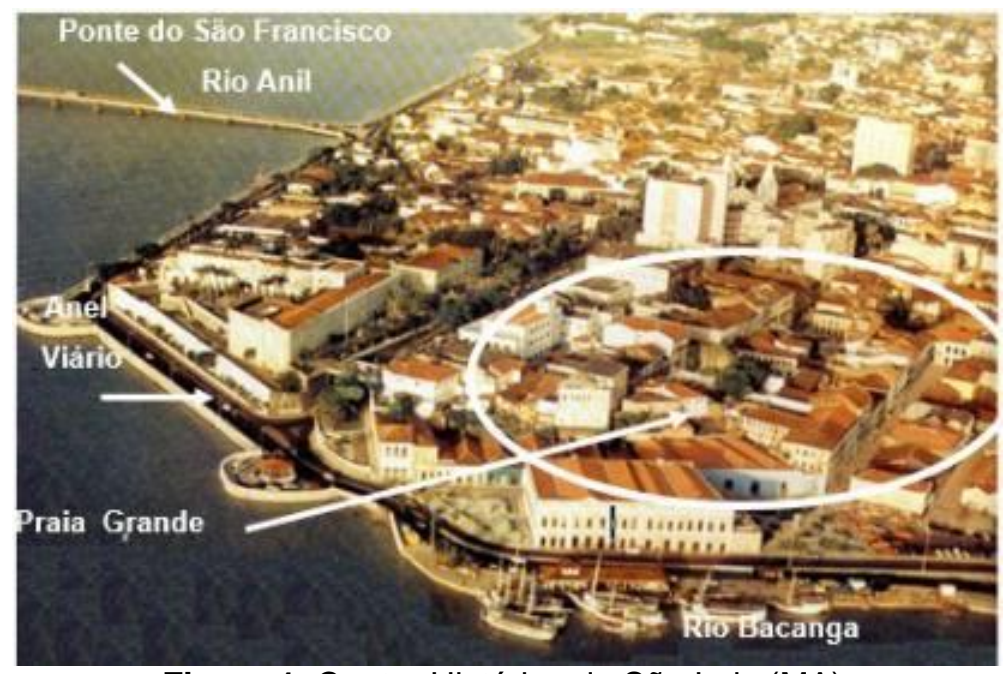

Figura 1: Centro Histórico de São Luis (MA).

Figure 1: São Luís's (MA, Brazil) Center Historic

Fonte: Gonçalves (2006).

Source: Gonçalves (2006).

Em 1987 o Projeto Reviver foi iniciado pelo Governo do estado buscando recuperar e revitalizar o conjunto arquitetônico do Centro Histórico de São Luís. Posteriormente, vieram as intervenções urbanas mais profundas, realizadas principalmente na área da Praia Grande e arredores. Foram beneficiadas 107.000 metros quadrados tombados pelo Patrimônio Histórico Nacional.

O conjunto da Praia Grande é formado por ruas, becos, travessas e escadarias que se constituíram por muitos anos no centro comercial de São Luís. Hoje, guarda a memória de um tempo de esplendor e opulência. É um patrimônio cultural único - orgulho, coração e alma da cidade (PATRIMÔNIO, 2009 apud SILVA; SILVA, 2010, p.12).

Os casarões em ruínas que não puderam ser efetivamente restaurados em seu traçado original, surgiram praças; as calçadas voltaram a ser largas e receberam pedras de cantaria, becos e escadarias sofreram amplas reformas, tendo sido removida também toda a camada de asfalto das ruas, que foram calçadas de paralelepípedos. Com o tempo, o local passou a ganhar forma e hoje abriga a Feira de Praia Grande, que ainda possui as armas do Império do Brasil na sua entrada. Em torno do centro comercial nasceram imponentes sobrados, além de belas casas com fachadas em azulejos, fazendo do lugar uma pequena Lisboa para os imigrantes portugueses. Formam a Praia Grande ruas, becos, travessas e escadarias históricas, como a Rua do Trapiche, o Beco da Alfândega, Travessa Fluvial, Beco da Prensa, Beco Catarina Mina, Rua da Estrela, Praça do Comércio, Rua do Giz e a Rampa do comércio.

Na Figura 2 vemos o Museu Casa da Festa ou Centro de Cultura Popular Domingos Vieira Filho, tem exposição do conjunto de coleções temáticas como das danças e folguedos e religiosidade (tambor de mina, festa do Divino Espírito Santo, ex-votos, santos, presépios); vestimentas e objetos usados em rituais populares e religiosos. 


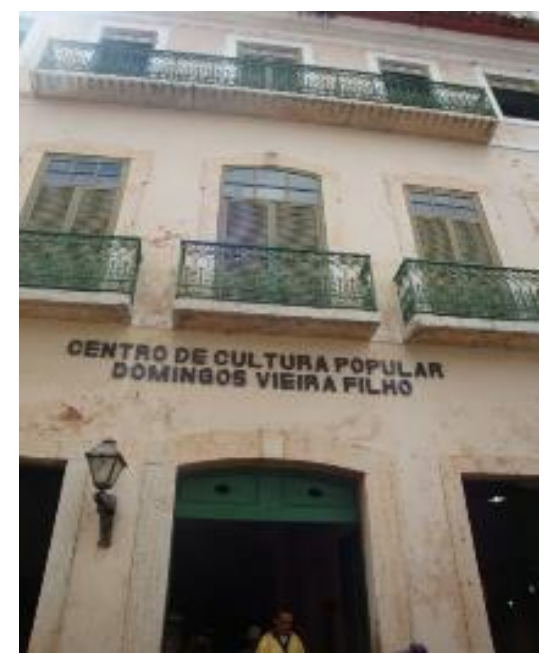

Figura 2: Museu Casa da Festa. Fonte: autores.

Figure 2: Casa de Festa Museum. Source: authors.

O acervo do bairro da praia grande é composto por varias edificações a maioria são do estilo colonial e muitas hoje utilizadas como centros de cultura e museus onde guardam a história e a cultura do Maranhão (Figuras 3 e 4).

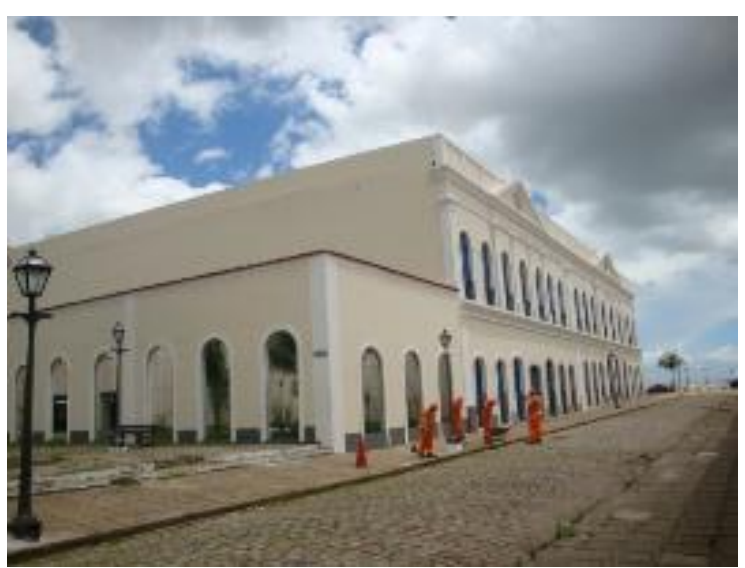

Figura 3: Casa do Maranhão.

Figure 3: Maranhão's House.

Fonte: autores.

Source: authors.

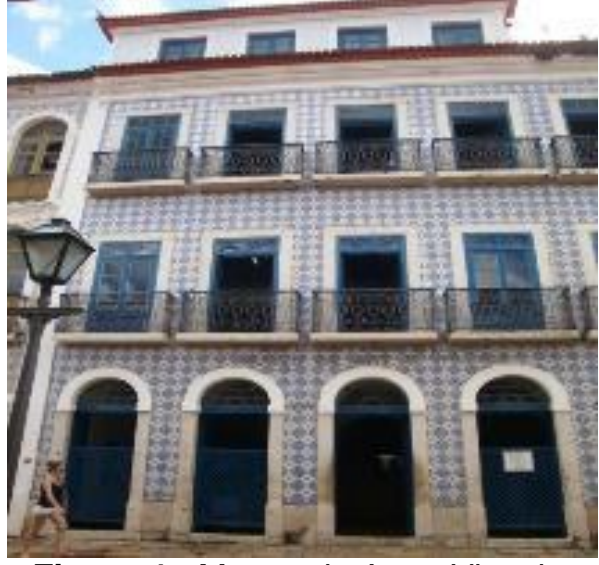

Figura 4: Museu de Artes Visuais. Figure 4: Visual Arts Museum.

Fonte: autores.

Source: authors.

É importante pensar que a partir das diversas modificações, o Bairro da Praia Grande se tornou um espaço destinado ao lazer cultural e turismo cultural, passamos de um bairro que era uma grande potência comercial, a dinâmica social e o comércio diminuíram e por fim tínhamos sobrados desocupados e deteriorados, o pontapé inicial para tornar o bairro de Praia Grande um bom lugar para seus habitantes foi o "Projeto Reviver", a partir dele aconteceu a restauração de grande parte do bairro e a Praia Grande passando assumir uma nova função: área de lazer com espaços para manifestações artístico-culturais. Posteriormente os Quadros 1, 2 e 3 apresentam os equipamentos de lazer culturais específicos que se destacam no Bairro em estudo, apontando suas descrições, endereço, horários de funcionamento bem como uma breve descrição do que no espaço é ofertado para seus visitantes. 
É importante ressaltar que o patrimônio material edificado do bairro contempla um número significativo de edifícios que possui potencial e podem ser trabalhados em relação ao turismo cultural, foram elencados nos Quadros 1,2 e 3 em função de sua atratividade e atividades desenvolvidas.

Quadro 1: Equipamentos de lazer do bairro da Praia Grande - Museus.

Table 1: Leisure facilities in the neighborhood of Praia Grande - Museums.

\begin{tabular}{|c|c|c|c|}
\hline $\begin{array}{c}\text { Equipamento } \\
\text { de lazer }\end{array}$ & Descrição do espaço & $\begin{array}{c}\text { Endereço } \\
\text { /funcionamento }\end{array}$ & Atividades ofertadas \\
\hline $\begin{array}{l}\text { Casa de } \\
\text { Nhozinho }\end{array}$ & $\begin{array}{l}\text { Inaugurado em } 7 \text { de junho de } \\
2002 \text {, O museu está } \\
\text { instalado em um dos mais } \\
\text { imponentes prédios coloniais } \\
\text { do Centro Histórico, com } \\
\text { quatro andares e fachada } \\
\text { recoberta de azulejos. O nome } \\
\text { do espaço é uma homenagem } \\
\text { ao artesão } \\
\text { maranhense Antônio Bruno } \\
\text { Pinto Nogueira, o Nhozinho } \\
\text { (1904-1974) que, ao longo da } \\
\text { vida, confeccionou brinquedos } \\
\text { e figuras do folclore em buriti. }\end{array}$ & $\begin{array}{l}\text { Rua Portugal, } 185, \\
\text { Praia Grande. } \\
\text { Terça à Sábado, } \\
\text { das } 9: 00 \text { às } 17: 30 \text { e } \\
\text { Domingo das } 9: 00 \mathrm{~h} \\
\text { às } 12: 30\end{array}$ & $\begin{array}{l}\text { No acervo da casa estão } \\
\text { inúmeras obras de Nhozinho, } \\
\text { com destaque para as } \\
\text { delicadas miniaturas de } \\
\text { personagens do Bumba-Meu- } \\
\text { Boi. Também estão expostos } \\
\text { objetos e artefatos do } \\
\text { cotidiano regional, como } \\
\text { pilões, carro de boi, } \\
\text { utensílios de pesca e } \\
\text { artesanato indígena. }\end{array}$ \\
\hline $\begin{array}{l}\text { Museu de Artes } \\
\text { Visuais. }\end{array}$ & $\begin{array}{l}\text { Ocupa um sobrado de fachada } \\
\text { revestida de azulejos } \\
\text { portugueses. Internamente é } \\
\text { ligado a um prédio da Rua da } \\
\text { Estrela, onde estão instaladas } \\
\text { uma pequena biblioteca e } \\
\text { Galeria Nagy Lajos. }\end{array}$ & $\begin{array}{l}\text { Rua Portugal, } \mathrm{n}^{0} \\
237, \text { Praia Grande. } \\
\text { Terça aos sábados, } \\
\text { das } 9: 00 \text { às } 17: 00\end{array}$ & $\begin{array}{l}\text { Exposição permanente, } \\
\text { constam objetos de artes } \\
\text { plásticas como quadros, } \\
\text { esculturas, gravuras, } \\
\text { desenhos e pinturas, rótulos } \\
\text { antigos e exemplares de } \\
\text { azulejos do séculos XVIII, } \\
\text { XIX e XX, de origem } \\
\text { portuguesa, francesa e } \\
\text { alemã. }\end{array}$ \\
\hline $\begin{array}{l}\text { Museu do } \\
\text { Negro. }\end{array}$ & $\begin{array}{l}\text { A Cafua das Mercês é um } \\
\text { espaço cultural destinado à } \\
\text { preservação da memória da } \\
\text { forte presença da cultura afro } \\
\text { no Maranhão. Funciona em } \\
\text { uma local onde, à época da } \\
\text { escravidão, era uma espaço } \\
\text { para depósito dos escravos, } \\
\text { desembarcados em São Luís. }\end{array}$ & $\begin{array}{l}\text { Rua Jacinto Maia, } \\
\text { no } 54, \text { bairro da } \\
\text { Praia Grande. } \\
\text { Segundas às } \\
\text { sextas, das } 9: 00 \text { às } \\
\text { 18:00 horas. }\end{array}$ & $\begin{array}{l}\text { No seu circuito de exposição } \\
\text { permanente, encontra-se uma } \\
\text { coleção de peças de arte } \\
\text { africana de grupos culturais } \\
\text { como Bambara, Dogon, } \\
\text { Senufo e outros, além dos } \\
\text { objetos da cultura afro-- } \\
\text { maranhense: indumentárias e } \\
\text { instrumentos musicais } \\
\text { utilizados em rituais } \\
\text { religiosos. }\end{array}$ \\
\hline $\begin{array}{l}\text { Centro de } \\
\text { Cultura Popular } \\
\text { Domingos Vieira } \\
\text { Filho ou Casa da } \\
\text { festa }\end{array}$ & $\begin{array}{l}\text { Inicialmente como Museu do } \\
\text { Folclore e Arte Popular e a } \\
\text { Biblioteca do Folclore, criados } \\
\text { no ano de } 1971 \text {, funcionando } \\
\text { inicialmente na Rua do } \\
\text { Ribeirão. Em maio de } 1982, \\
\text { foi finalmente inaugurado, no } \\
\text { sobrado de quatro pavimentos, } \\
\text { do século XIX, como Centro de } \\
\text { Cultura Popular Domingos } \\
\text { Vieira Filho, uma justa } \\
\text { homenagem ao grande escritor } \\
\text { maranhense. }\end{array}$ & $\begin{array}{l}\text { Rua do Giz no } 221 \text {, } \\
\text { Praia Grande. } \\
\text { Terça a Domingo, } \\
\text { das 9:00 às } 17 \mathrm{~h}\end{array}$ & $\begin{array}{l}\text { Este circuito de exposição } \\
\text { tem mostras do conjunto de } \\
\text { coleções temáticas como: } \\
\text { danças e folguedos, } \\
\text { religiosidade (tambor de } \\
\text { mina, festa do Divino Espírito } \\
\text { Santo, ex-votos, santos, } \\
\text { presépios); vestimentos e } \\
\text { objetos usados em rituais } \\
\text { populares e religiosos. }\end{array}$ \\
\hline $\begin{array}{l}\text { Museu e Centro } \\
\text { de Pesquisa de } \\
\text { História Natural } \\
\text { e Arqueologia do } \\
\text { Maranhão }\end{array}$ & $\begin{array}{l}\text { Museu e Centro de Pesquisa } \\
\text { de História Natural e } \\
\text { Arqueologia do Maranhão. } \\
\text { Atende as pesquisas na área } \\
\text { de paleontologia, arqueologia e } \\
\text { disciplinas afins. }\end{array}$ & $\begin{array}{l}\text { Rua do Giz, } 59 \\
\text { Praia Grande } \\
\text { Segunda à sexta, } \\
\text { das } 14: 00 \text { às } 18: 00\end{array}$ & $\begin{array}{l}\text { Esse espaço de visitação } \\
\text { guarda acervo que inclui } \\
\text { preciosidades ferramentas, } \\
\text { cerâmicas, materiais líticos, } \\
\text { azulejos, além de outras } \\
\text { relíquias do passado, } \\
\text { encontra-se o acervo de } \\
\text { povos indígenas de milhares } \\
\text { de anos de fósseis e réplicas } \\
\text { de espécies pré-históricas } \\
\text { encontradas no Maranhão. }\end{array}$ \\
\hline
\end{tabular}


Quadro 2: Equipamentos de lazer do bairro da Praia Grande - Casas de Cultura e Espaços diversos.

Table 2: Leisure facilities in the neighborhood of Praia Grande - Miscellaneous Culture and Spaces Homes

\begin{tabular}{|c|c|c|c|}
\hline $\begin{array}{c}\text { Equipamento de } \\
\text { lazer }\end{array}$ & Descrição do espaço & $\begin{array}{c}\text { Endereço } \\
\text { /funcionamento }\end{array}$ & Atividades ofertadas \\
\hline $\begin{array}{l}\text { Casa de Cultura } \\
\text { Huguenone } \\
\text { Daniel de La } \\
\text { Touche }\end{array}$ & $\begin{array}{l}\text { Fundada em } 08 \text { de setembro de } \\
2014 \text {, divulga a histórica da } \\
\text { fundação da cidade de São Luís }\end{array}$ & $\begin{array}{l}\text { Beco Catarina } \\
\text { mina, } 128 \text {, Praia } \\
\text { Grande } \\
\text { segunda a sabado } \\
10 \text { as } 12 \text { e } 14 \text { as } 18\end{array}$ & $\begin{array}{l}\text { Funciona de nas segunda } \\
\text { com aulas de musica e } \\
\text { quntas aula de cinema e as } \\
\text { sextas musica ao vivo }\end{array}$ \\
\hline $\begin{array}{l}\text { Espaço Cultural } \\
\text { Catarina Mina }\end{array}$ & $\begin{array}{l}\text { O local é um casarão colonial } \\
\text { de } 1697 \text {. A Companhia de } \\
\text { Cultura Popular Catarina Mina } \\
\text { foi fundada em março de } 2000 \text {. } \\
\text { A Companhia é uma instituição } \\
\text { sem fins lucrativos, de caráter } \\
\text { sócio cultural e educacional. }\end{array}$ & $\begin{array}{l}\text { Rua Portugal, } \\
243 \mathrm{~A} \text {, Praia } \\
\text { Grande } \\
\text { Aberto de segunda } \\
\text { a sabado } 9: 00 \text { as } \\
17: 00\end{array}$ & $\begin{array}{l}\text { O Espaço Catarina Mina é } \\
\text { uma casa de shows do } \\
\text { Centro Histórico de São } \\
\text { Luís. Mantém a proposta } \\
\text { de promover eventos que } \\
\text { valorizem a cultura local e a } \\
\text { diversão }\end{array}$ \\
\hline Casa do Povo & $\begin{array}{l}\text { É uma galeria de arte e } \\
\text { educação }\end{array}$ & $\begin{array}{l}\text { Rua da estrela, } \\
163 \text { Praia Grande } \\
\text { segunda a sabádo } \\
8: 00 \text { ás } 17: 00\end{array}$ & $\begin{array}{l}\text { Possui cursos, capoeira, } \\
\text { pintura em tela e artesanato } \\
\text { índigena. }\end{array}$ \\
\hline $\begin{array}{l}\text { Morada das } \\
\text { Artes }\end{array}$ & $\begin{array}{l}\text { Localizado na residência de } \\
\text { artitas plásticos }\end{array}$ & $\begin{array}{l}\text { Rua do Trapiche, } \\
\text { S/N }\end{array}$ & $\begin{array}{l}\text { Espaço interativo cultural } \\
\text { de artes e pintura }\end{array}$ \\
\hline $\begin{array}{l}\text { Casa das } \\
\text { Tulhas. }\end{array}$ & $\begin{array}{l}\text { A "Casa das Tulhas" foi } \\
\text { construída em } 1820 \text { com a } \\
\text { finalidade de ser um espaço } \\
\text { onde os lavradores pudessem } \\
\text { guardar suas mercadorias e } \\
\text { vendê-las pelo melhor preço. } \\
\text { Em } 1859 \text {, assumiu a } \\
\text { responsabilidade de retirar seus } \\
\text { escombros para, em seu lugar, } \\
\text { construir a atual Feira da Praia } \\
\text { Grande. } \\
\text { Circundado por casas } \\
\text { comerciais, na parte externa. }\end{array}$ & $\begin{array}{l}\text { R. da Estrela, } \\
n^{\circ} 184 \text {, Praia } \\
\text { Grande. } \\
\text { Segunda a Sexta, } \\
\text { das } 7: 00 \text { às } 20 \mathrm{~h}, \\
\text { Sábado, das } 7: 00 \\
\text { às 18:00 e } \\
\text { Domingo, das } 7: 00 \\
\text { às 15:00. }\end{array}$ & $\begin{array}{l}\text { A Feira tem quatro } \\
\text { entradas, sendo que na } \\
\text { principal, se pode ver, ao } \\
\text { centro da bandeira de ferro } \\
\text { aberta em arco, as iniciais } \\
\text { CM, alusivas à Confiança } \\
\text { Maranhense e, logo abaixo, } \\
\text { a data } 1861 \text {, talvez alusiva } \\
\text { ao ano da conclusão. } \\
\text { Quando se deseja comprar } \\
\text { artigos: doces, licores, } \\
\text { tiquiras, cachaças do } \\
\text { interior, farinhas, panelas } \\
\text { de ferro ou de alumínio } \\
\text { reciclado, cordas, arames, } \\
\text { sal grosso..., a Feira da } \\
\text { Praia Grande é o local. }\end{array}$ \\
\hline Galeria Reviver & $\begin{array}{l}\text { Localizado em um prédio } \\
\text { colonial }\end{array}$ & $\begin{array}{l}\text { Rua da estrela } \\
\text { 175, Praia Grande. } \\
\text { Segunda a Sexta, } \\
\text { das } 7: 00 \text { às } 20 \mathrm{~h}, \\
\text { Sábado e Domingo } \\
\text { das } 7: 00 \text { às } 15: 00 .\end{array}$ & $\begin{array}{l}\text { Espaço interativo } \\
\text { compostos por diversas } \\
\text { lojas de artesanato e } \\
\text { lembranças do estado do } \\
\text { Maranhão }\end{array}$ \\
\hline
\end{tabular}


Quadro 3: Equipamentos de lazer do bairro da Praia Grande - Teatros, cinemas e centros de encontro.

Table 3: Leisure facilities in the neighborhood of Praia Grande - Theatres, cinemas and centers against.

\begin{tabular}{|c|c|c|c|}
\hline $\begin{array}{l}\text { Equipamento } \\
\text { de lazer }\end{array}$ & Descrição do espaço & $\begin{array}{c}\text { Endereço } \\
\text { /funcionamento }\end{array}$ & Atividades ofertadas \\
\hline $\begin{array}{l}\text { Teatro João do } \\
\text { Vale }\end{array}$ & $\begin{array}{l}\text { Criado no dia } 7 \text { de março de } \\
1995 \text {, é um antigo galpão } \\
\text { comercial adaptado para o } \\
\text { teatro em homenagem ao } \\
\text { grande compositor e cantor } \\
\text { maranhense João do Vale. }\end{array}$ & $\begin{array}{l}\text { Rua da Estrela, s/n, } \\
\text { Terça a Domindo, } \\
\text { das 13:00 às 19:00. }\end{array}$ & $\begin{array}{l}\text { Possui capacidade de lotação } \\
\text { para um público aproximado de } \\
400 \text { espectadores. Tem por } \\
\text { finalidade a realização de } \\
\text { programações artístico-culturais } \\
\text { em regime de multi-uso } \\
\text { ocupacional, promovendo, } \\
\text { apoiando e difundindo a arte e a } \\
\text { cultura nas suas diferentes } \\
\text { manifestações e formas de } \\
\text { expressão. }\end{array}$ \\
\hline $\begin{array}{l}\text { Centro de } \\
\text { Criatividade Odylo } \\
\text { Costa Filho. }\end{array}$ & $\begin{array}{l}\text { Tem sua origem no antigo Centro de } \\
\text { Artes e Comunicações Visuais, } \\
\text { criado pela Lei no } 4.102 \text {, de } 06 \text { de } \\
\text { novembro de } 1979 \text {. No final da } \\
\text { década de } 80 \text {, sofreu intensa } \\
\text { reforma, sendo então aparelhado } \\
\text { com teatro e cinema. O Centro } \\
\text { ocupa um espaço, onde outrora } \\
\text { funcionavam tradicionais casas } \\
\text { comerciais atacadistas. Foi } \\
\text { recentemente reformado e } \\
\text { climatizado }\end{array}$ & $\begin{array}{l}\text { Rua da Alfândega e } \\
\text { Beco dos Catraeiros } 200 \\
\text { Praia grande Segunda a } \\
\text { Terça no horário } \\
\text { matutino e vespertino }\end{array}$ & $\begin{array}{l}\text { Por força regimental, tem o } \\
\text { objetivo de promover a produção e } \\
\text { a difusão artística do Estado, nas } \\
\text { mais diversas formas de } \\
\text { expressão, passando pela música, } \\
\text { dança, artes plásticas, literatura e } \\
\text { artes visuais em geral. } \\
\text { oferecendo cursos e oficinas nos } \\
\text { mais diversos campos das artes, } \\
\text { enquanto suas casas de } \\
\text { espetáculo, o cinema e o teatro, } \\
\text { realizam sessões no horário } \\
\text { noturno }\end{array}$ \\
\hline Cine Praia Grande & $\begin{array}{l}\text { Localizado dentro do Centro de } \\
\text { criatividade Odylo Costa Filho. }\end{array}$ & $\begin{array}{l}\text { Rua da Alfândega e } \\
\text { Beco dos Catraeiros }\end{array}$ & $\begin{array}{l}\text { Possui capacidade para } 120 \\
\text { lugares, realizam sessões no } \\
\text { horário noturno }\end{array}$ \\
\hline $\begin{array}{l}\text { Teatro Alcione } \\
\text { Nazaré }\end{array}$ & $\begin{array}{l}\text { Localizado dentro do Centro } \\
\text { de criatividade Odylo Costa } \\
\text { Filho. }\end{array}$ & $\begin{array}{l}\text { Rua da Alfândega e } \\
\text { Beco dos Catraeiros }\end{array}$ & $\begin{array}{l}\text { Casa de espetáculo com s } \\
\text { apresentações populares no } \\
\text { horário noturno }\end{array}$ \\
\hline
\end{tabular}

A partir da evolução e do desenvolvimento que São Luís sofreu percebemos que a preservação de alguns dos seus primeiros prédios e monumentos localizados no Centro, hoje Centro Histórico, eles contam a história dos primórdios da cidade com grande acervo da cultura popular, existindo muito potencial para o desenvolvimento do Turismo Cultural devendo despertar não somente o interesse apenas dos turistas, mas também da população local.

Os principais resultados da pesquisa apontam para um grande acervo de equipamentos de lazer no centro histórico como apontam nos Quadros 1, 2 e 3, observados anteriormente, mas que infelizmente pouco ou nada estão sendo utilizados para esse fim, através de passeios de observação por esses espaços percebemos um lugar riquíssimo de espaços, prédios coloniais, cultura viva popular, portanto os equipamentos existem, mas não estão sendo direcionados para serem aproveitados dentro do que seu valor impõe, observamos os espaços vazios, principalmente os museus e casas de cultura popular, visitantes (prováveis turistas) nas principais ruas do Bairro da Praia Grande, olham esses espaços, às vezes entram, por vezes sentem-se perdidos pela falta de orientação e direcionamento.

Apontamos algumas problemáticas observadas nesses equipamentos como inflexibilidade nos horários e dias de abertura para o público, a pouca divulgação ou nada divulgação e dinamização desse espaço bem com a falta de uma programação catalogada e divulgada para atrair os visitantes turistas e locais. 


\section{Considerações finais}

O Lazer cultural é um segmento em desenvolvimento e uma prática bastante utilizada em vários destinos turísticos, inclusive em cidades brasileiras. A cultura é capaz de atrair fluxos de turistas, entendemos então que São Luis ainda não desenvolveu essa área como deveria e não atentou em demonstrar as possibilidades de atividades que existem em seu Centro Histórico.

Para trabalhar e desenvolver o segmento, é necessário que haja uma estrutura básica para a propagação desses elementos, a pouca divulgação além de quesitos como o acesso aos espaços, à segurança e acesso as informações bem como a inflexibilidade nos horários e dias de abertura para o público são problemáticas que precisam ser sancionadas.

É importante que as pessoas possam locomover-se pelas ruas e ter as indicações dos espaços, dos equipamentos de lazer, museus, teatros, centros de cultura, sejam disponibilizadas informações a respeito do patrimônio para que o visitante tenha a sua descrição básica, sinalizações dos espaços adequadamente para auxiliar no seu deslocamento, bem como pessoas preparadas para receber os visitantes e gerenciar seu deslocamento.

A população principalmente a local desconhece o valor de sua história, há uma deficiência não apenas nas questões estruturais do centro histórico, mas o reconhecimento da importância que o centro histórico possui e o seu potencial pouco explorado sistematicamente.

A sistematização desse espaço para o ideal de lazer seriam apresentações do equipamentos e visitas de forma mais dinâmica, integrando os residentes da praia grande. A população local precisa interagir com os turistas, não apenas para vendas de artigos locais, mas como um todo em outras atividades, a realização de mais trabalhos de educação patrimonial é algo importante para que a comunidade também dele se aproprie se identificando para valorizar esses espaços, sendo assim preservados e se tornem mais atrativos aos turistas, mostrando os valores da cultura local e a importância do centro histórico como objeto de memória na vida das pessoas e na formação da sua história.

Pensamos na utilização desses equipamentos de lazer de forma atrativa para os visitantes, fotos, explanação sobre os lugares, fatos e curiosidades sobre o contexto do local. Utilizar melhor as tecnologias interativas como material multimídia que poderia mostrar brevemente o centro histórico e algumas informações adicionais sobre o espaço bem como a apreciação das danças populares e a manifestação artística da cidade.

Enfim dinamizar os equipamentos de lazer do Centro Histórico para que estejam efetivamente prontos para receber o público no intuito de acrescentar e desenvolver o centro histórico. A pesquisa foi feita no sentido de identificar os equipamentos desse espaço e potencialidades de lazer no bairro da Praia Grande no Centro Histórico de São Luis (MA) analisando e discutindo o papel do lazer para o desenvolvimento de espaços de patrimônio histórico-cultural. 


\section{Referências Bibliográficas}

ANTUNES, R. Tempo de Trabalho e Tempo Livre: algumas teses para discussão. In: BRUHNS, H.T.; GUTIERREZ, G.L. (Orgs.) Representações do Lúdico: II ciclo de debates "lazer e motricidade". Campinas: Autores Associados, 2001.

AZEVEDO, J. Turismo cultural: traços distintivos e contribuições para o desenvolvimento endógeno. In: IRVING, M.A.; AZEVEDO, J. (Orgs). Turismo e o desafio da sustentabilidade. São Paulo: Futura, 2001, p. 149-165.

ARANTES, O.B.F. Uma estratégia fatal. A cultura nas novas gestões urbanas. In: ARANTES, O.; VAINER, C.; MARICATO, E. A Cidade do pensamento único: desmanchando consensos. Petrópolis, RJ: Vozes, 2000 p- 11-74.

BURNETT, C.F.L. Da cidade unitária à metrópole fragmentada: crítica à constituição da São Luís moderna, comunicação apresentada no IX Seminário de História da Cidade e do Urbanismo, São Paulo, SP, 4 a 6 set. 2006.

BURNETT, C.F.L. O Estado e o Patrimônio Cultural: políticas de elitização e popularização na área central de São Luís. III Jornada internacional de políticas públicas. Ago. 2007

CARVALHO, K.D.; SIMÕES, M.L.N. Analise do modelo de preservação do Centro Histórico de São Luís do Maranhão: uso social e uso turístico. Revista Turismo Visão e Ação - Eletrônica, Vol. 14 - no 2 - p. 196-213- / mai-ago 2012.Disponível em: www.univali.br/revistaturismo

CARVALHO, K.D. Turismo e preservação do patrimônio cultural na visão dos moradores do bairro da Praia Grande em São Luís/MA. Revista Brasileira de Pesquisa em Turismo, v. 3, n. 1, p. 25-45, abril 2009.

CRUZ NETO, O. O trabalho de campo como descoberta e criação. In: MINAYO, M.C.S. (org.) Pesquisa social: teoria, método e criatividade. Petrópolis, RJ: Vozes, 1994.

DUMAZEDIER, J. Lazer e Cultura Popular. 3. ed. São Paulo: Perspectiva, 2000.

GONÇALVES, D.S. Moro em edifício histórico, e agora?. Avaliação pósocupação de habitações multifamiliares no Centro Histórico de São Luís - MA. (Dissertação Mestredo). Universidade Federal do Rio Grande do Norte, 2006.

GOMES, C.L. Dicionário crítico do Lazer. Belo Horizonte: Autêntica Editora, 2004.

MARTIGNONI, L. Lazer no assentamento oito de junho: análise a partir da multifuncionalidade da agricultura. Dissertação de mestrado apresentada ao Programa de Pós-Graduação em Desenvolvimento Regional. 2013. Dissertação (Mestrado em Desenvolvimento Regional) Programa de PósGraduação Universidade Técnologica Federal do Paraná.

MARCELLINO, N.C. Lazer e Humanização. 2. ed. Campinas: Papirus, 1995.

MARCELLINO, N.C.. Estudos do Lazer: uma introdução. 4.ed. Campinas: Autores Associados, 2006.

MINAYO, M.C.S. O desafio do conhecimento: pesquisa qualitativa em saúde. São Paulo, Hucitec, 1999

PEIXOTO, P.. Centros históricos e sustentabilidade cultural das cidades. Faculdade de Letras da Universidade do Porto, 2003. 
RICHARDSON, R.J. Pesquisa social: métodos e técnicas. São Paulo, SP: Atlas, 1999.

SEBASTIÃO, A.S. Planejamento estratégico para o Centro Histórico de Torres Vedras. Dissertação de Mestrado. Universidade de Lisboa. Instituto de Geografia e Ordenamento do Território. Mestrado em Geografia - Gestão do Território e Urbanismo, 2010

SILVA, G.P.; SILVA, E.L.S. A utilização do patrimônio como cenário para o consumo e a fruição turística: estratégias de produção de imagem do bairro Praia Grande-MA. Cuadernos de vivienda y urbanismo,Vol.3, No. 5, 2010. Disponível em: http://www.javeriana.edu.co/viviendayurbanismo

VENANCIO, M.W.C. As Razões, as paixões, as contradições de morar no lugar antigo: uma investigação sobre o habitar contemporâneo no patrimônio cultural urbano. Pólo Santo Antônio, São Luís, Maranhão. 2002. Dissertação (Mestrado em Desenvolvimento Urbano). Programa de Pós- Graduação Universidade Federal de Pernambuco. Recife.

VENANCIO, M.W.C. A invenção do centro histórico de São Luís, Maranhão. Universidade Estadual do Maranhão

VENANCIO, M.W.C. De quem é o patrimônio da humanidade? - Um estudo sobre a vida cotidiana no centro histórico de São Luís. XII Encontro da Associação Nacional de Pós -Graduação e pesquisa em planejamento urbano e regional, Belém - Pará - Brasil, 2007.

\section{Nota:}

${ }^{1}$ O Centro Histórico da cidade de São Luís, capital do Maranhão, é o nono monumento histórico-cultural do país incluído na lista do Patrimônio Mundial Cultural e Natural da Unesco, segundo decisão da assembleia geral do Comitê do Patrimônio Mundial daquela Instituição, reunida em Nápoles, Itália, em 4 de dezembro de 1997.

Andréia Maciel Santos Moutinho: Instituto Federal do Maranhão São Luís, MA, Brasil.

E-mail: andreia_m_santos@yahoo.com.br

Link para o currículo Lattes: http://lattes.cnpq.br/2846913385170559

Klautenys Dellene Guedes Cutrim: Universidade Federal do Maranhão São Luís, MA, Brasil.

E-mail: kdguedes@yahoo.com.br

Link para o currículo Lattes: http://lattes.cnpq.br/4310600393313804

Data de submissão: 28 de abril de 2015

Data de recebimento de correções: 17 de fevereiro de 2016

Data do aceite: 17 de fevereiro de 2016

Avaliado anonimamente 